\title{
EVOKED EMOTION IN MARITAL THERAPY: NECESSARY OR EVEN USEFUL?
}

\author{
James C. Coyne \\ University of Michigan Medical School
}

Greenberg and Johnson's (1986) call for a greater emphasis on emotion in marital therapy is another indication that what has been called the cognitive revolution in psychotherapy is fizzling. Despite impressive accomplishments, the cognitive perspective has been beset by conceptual confusion (Coyne, 1982) and empirical findings which suggest that explicitly cognitive interventions add little to the benefits of simply getting patients to interact differently with their environments (Berman, Miller, \& Massman, 1985; Miller \& Berman, 1983). In many respects, Greenberg and Johnson's model of therapy may be seen as a reaction to the excesses and deficiencies of the cognitive approach.

The history of psychology suggests that an overemphasis on either cognition or emotion (or motivation, for that matter) leads to an inevitably fragmented, distorted, and incomplete view of the person-in-context (Coyne, 1981). Greenberg and Johnson's theoretical model is in an early stage of development, and it remains to be seen to what extent it is a fresh solution or a mere perpetuation of the problems of the cognitive perspective. However, it is possible to take a pragmatic stance and examine what their model of therapy identifies as the opportunities and constraints that face the therapist working with couples. In particular, the model differs in key ways from a strategic approach to marital therapy (Coyne, 1984a, in press), and a comparison could prove informative.

Greenberg and Johnson argue for the necessity of accessing and exploring the unacknowledged emotion that is assumed to underly a couple's interactional patterns, and then assisting them to express this to each other. Such an evocation of affect stands in sharp contrast to the strategic therapist's investment in keeping sessions "cool" and "low-key," frequently even by interviewing partners in conflictful marriages separately (Coyne, 1984b). For the strategic therapist, the session is typically seen as a staging area for change in the couple's everyday life, rather than the place where change is to occur. There is a concern that a heated emotional exchange in a session may reflect the artificiality of therapy as an interactional context, and, in particular, the presence of the therapist as a possible ally, referee, or commentator. Such exchanges may not be representative of what occurs outside of therapy, and may leave the couple polarized and less prepared to undertake any initiative for change. Given the tasks of a strategic therapist, emotional displays in a session are generally viewed as a distraction, and they may interfere with the therapist's ability to gather information about how the problem is being maintained in the couple's everyday life, partition this problem into manageable issues, set goals, and redirect the couple's miscarried efforts to resolve their difficulties.

James C. Coyne, PhD, is an Associate Professor, Department of Family Practice, University of Michigan Medical School, Ann Arbor, MI 48106.

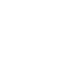


Greenberg and Johnson contend that calm discussion is unlikely to influence a couple's emotional response to each other. They argue that learning is state-dependent, and that therefore the couple should ideally be in the emotional state that is targeted for change. The notion of state dependent learning (Bower, 1981) received considerable attention a few years ago. However, there has been considerable difficulty replicating the relevant experimental studies, and the concept's originator now considers it "an evanescent will-of-the wisp" (Bower \& Mayer, 1985, p. 41). Furthermore, numerous studies demonstrate that calmly provided reframes can indeed alter affective and even physiological responses in subsequent stressful encounters (Lazarus, Coyne \& Folkman, 1982). Such research does not contradict Greenberg and Johnson's contention that evoking emotion in a session is useful, but it does suggest that it is not necessary.

Consistent with their assumption that emotion structures interactions, Greenberg and Johnson describe how the expression of emotional vulnerability by one person may evoke compassion and renewed efforts at intimacy by the spouse. Alternatively, expression of anger may be used to establish clear boundaries and set limits on behavior. Whether vulnerability or anger will be most facilitative of positive change tends to be a complex clinical judgment; furthermore, a person's expression may be more a matter of strategic self-presentation than an indication of an enduring attitude toward the spouse. Grappling with these difficulties, Greenberg and Johnson propose a taxonomy of emotional response to guide the therapist in making decisions about when and how to intervene. A key assumption of their approach is that a person is likely to be unaware of his or her basic emotional response and may need assistance in identifying it.

Strategic therapists should have no problem with the idea that emotionally charged situations may be reframed or relabeled in a way that leads to a different structuring of the interaction in a couple. However, strategic therapists generally stop short of telling patients that they feel differently than they believe that they do. Aside from philosophical difficulties with the theoretical notion of emotions out of awareness (Hampshire, 1959), patients may legitimately resent the suggestion that their anger is really vulnerability or vice versa. Perhaps more importantly, the a priori assumption that emotional vulnerability will always invite compassion rather than attack and exploitation, is likely to prove naive. Greenberg and Johnson's model suggests that the issue is largely one of the authenticity of the emotion in question, and that this is where the critical clinical judgment is to be made, but this appears to be overly optimistic and slights the importance of interactional context: a spouse may react negatively to a person's distress, whether it is expressed as anger or vulnerability, or seen as authentic or not.

Greenberg and Johnson's model is innovative and it offers creative suggestions for how to resolve marital distress. Yet, it may ask too much of many couples seeking therapy. Partners have difficulty expressing emotion and responding to each other's expression of emotion. They may define this as the problem and actively seek change. However, they may not, and the requirement that they deal with emotion in a particular way as a precondition for resolving their problems as they define them may be an overwhelming barrier to achieving their goals.

Strategic therapists acknowledge and respect diversity in relationships, and recognize the necessity of working flexibly on this basis. Better communication, greater receptivity to each other's feelings, and more comfort in disclosing one's own feelings, would benefit many couples. However, a vigorous and direct effort to achieve these goals may be precisely the attempted solution that keeps a couple miserable. The demand that someone communicate more tends to be inhibiting, and the demand that one (spontaneously) show emotion can be an untherapeutic double bind. Particularly when there has been a polarization around differences about the desired level of intimacy or emotional expressiveness, too central a focus on the evocation of emotion may inhibit 
change. Change in the emotional climate of a relationship may more readily be accomplished when the couple has been assisted in going beyond vague definitions of their problems in terms of communication or emotional expressiveness, and are working together in the context of having some successful interactions around the resolution of more concrete issues. In the case of couples with a depressed person, there are some recent therapy outcome data that suggest that efforts aimed directly at an increase in intimacy and the sharing of emotion may be counterproductive and even destructive (Waring, 1984).

All theories of therapeutic change involve unacknowledged judgments about how people should lead their lives. Greenberg and Johnson offer a model that should be appealing to many couples, and for these couples it may serve as an effective metaphor for change. However, the model's sweeping prescriptions for how marital therapists should proceed, and what effects they should seek, might best be interspersed with caveats about "some couples, some of the time." In general, theorists and therapists should be cautious about the implicit assumptions and value judgments packed into the concept of emotion, and about the pitfalls of accepting emotion as a ding an sich representing something more than an inference about the nature of the person's relationship to the environment. The danger is that we will replace the narrowness, reductionism, and misplaced concreteness of an overly cognitive perspective with the narrowness, reductionism, and misplaced concreteness of too exclusive a focus on emotion.

\section{REFERENCES}

Berman, J. S., Miller, R. C. \& Massman, P. J. (1985). Cognitive therapy versus systematic desensitization: Is one treatment superior? Psychological Bulletin, 97, 451-461.

Bower, G. H. (1981). Mood and memory. American Psychologist, 36, 129-148.

Bower, G. H. \& Mayer, J. D. (1985). Failure to replicate mood-dependent retrieval. Bulletin of the Psychonomic Society, 23, 39-42.

Coyne, J. C. (1981). Putting Humpty Dumpty back together: cognition, emotion, and motivation in consumer research. Advances in Consumer Research, 9, 153-155.

Coyne, J. C. (1982). A critique of cognitions as causal entities with particular reference to depression. Cognitive Therapy and Research, 6, 3-13.

Coyne, J. C. (1984a). Strategic therapy with married depressed persons: agenda, themes, and interventions. Journal of Marital and Family Therapy, 10, 53-62.

Coyne, J. C. (1984b). Introducing structural interventions into strategic therapy: A caution. Journal of Systemic and Strategic Therapies, 3, 23-27.

Coyne, J. C. (in press). Marital therapy for depression: a strategic perspective. In N. S. Jacobson \& A. S. Gurman (Eds.), Clinical Handbook of Marital Therapy. New York: Guilford Press.

Hampshire, S. (1959). Thought and action. New York: Viking Press.

Lazarus, R. S., Coyne, J. C. \& Folkman, S. (1982). Cognition, emotion, and motivation: the doctoring of Humpty-Dumpty. In R. W. Neufeld (Ed.), Psychological Stress and Psychopathology. New York: McGraw-Hill.

Miller, R. C. \& Berman, J. S. (1983). The efficacy of cognitive behavior therapies: a quantitative review of the research evidence. Psychological Bulletin, 94, 39-53.

Waring, E. T. (1984). Personal communication. 